\title{
Correlation of OGR1 with proliferation and apoptosis of breast cancer cells
}

\author{
JIANGUO ZHANG ${ }^{1 *}$, LEI CHE ${ }^{2 *}$, WENKAI SUN ${ }^{1}$, JIAN SHANG $^{1}$, MIN HAO $^{1}$ and MENGZI TIAN ${ }^{1}$ \\ Departments of ${ }^{1}$ Breast and Thyroid Surgery and ${ }^{2}$ Anesthesia and Surgery, \\ Dongying People's Hospital, Dongying, Shandong 257091, P.R. China
}

Received June 13, 2018; Accepted February 4, 2019

DOI: $10.3892 / 01.2019 .10121$

\begin{abstract}
Effects of ovarian cancer G-protein-coupled receptor 1 (OGR1) protein on proliferation and apoptosis of breast cancer cells, as well as its molecular mechanism were investigated. The MCF-7 cell line highly expressed OGR1 was constructed by transient transfection of eukaryotic expression vector using breast cancer cells. At the same time, cells were transfected with empty vector as controls. The effects of highly expressed OGR1 on cell growth, proliferation, apoptosis and other abilities were identified. In addition, the effects of highly expressed OGR1 on serine-threonine kinase $(\mathrm{AKT}), \mathrm{p} 53$ and other genes were studied. It was proved in apoptosis experiment that highly expressed OGR1 protein in breast cancer cells could effectively increase the proportion of apoptosis of cells. Cell proliferation experiment revealed that the growth and proliferation abilities of breast cancer cells with highly expressed OGR1 were inhibited to some extent, compared with those of breast cancer cells with low expression of OGR1. Results of western blotting showed that the gene and protein expression levels of p53 in breast cancer cells with highly expressed OGR1 were increased. There was no significant difference in protein expression of AKT between breast cancer cells with low expression of OGR1 and those with highly expressed OGR1. However, the protein content of phosphorylated-AKT (p-AKT) in breast cancer cells with highly expressed OGR1 was lower than that in breast cancer cells with low expression of OGR1. The proliferation and apoptosis of breast cancer cells are influenced by the changes of OGR1 expression, which are correlated with the gene expression levels of AKT and p53 to some extent, but the detailed molecular mechanism requires additional study.
\end{abstract}

Correspondence to: Dr Wenkai Sun, Department of Breast and Thyroid Surgery, Dongying People's Hospital, 317 Nanyi Road, Dongying, Shandong 257091, P.R. China

E-mail: ooza028@163.com

*Contributed equally

Key words: OGR1, breast cancer cell, AKT, p53

\section{Introduction}

According to the statistics of the American Cancer Society, in 2015, there were more than 230,000 new cases of breast cancer diagnosed in the United States, and approximately 40,000 patients died of breast cancer (1). It is estimated that one in eight women will develop breast cancer in their lifetime, and it is also estimated that approximately one in 37 women with breast cancer will die of the disease, most of whom are aged over 45 years. The survival rate of patients with non-metastatic breast cancer is relatively high (98.5\%), but that of patients with metastatic breast cancer is notably decreased $(24 \%)(2,3)$. Among patients with metastatic breast cancer, approximately $20-30 \%$ of them have metastases of cancer cells to lung tissue, liver and other sites, which then develop into lung cancer and liver cancer, ultimately leading to death of the patient (4-6). Breast cancer metastases to the brain are observed in approximately $10-20 \%$ of women, resulting in a decrease in life expectancy by 8-30 months (7-11). There are many causes of breast cancer, among which one of the more important risk factors is individual gene mutations including p53 and phosphatase and tensin homolog deleted on chromosome ten protein (PTEN) genes. The study was approved by the Ethics Committee of Dongying People's Hospital (Dongying, China).

As a member of $\mathrm{G}$ protein coupled receptor family, ovarian cancer G-protein-coupled receptor 1 (OGR1) is named for its first discovery in ovarian cancer cell line HEY. The expression of OGR1 messenger ribonucleic acid (mRNA) is detected in many normal tissues. The function and ligand of OGR1 have not been unified. Some studies have proved that OGR1 has proton sensing function, with proton as its ligand (12). Other studies have demonstrated that OGR1 is able to sense changes in proton concentration and maintain the balance of cell potential of hydrogen $(\mathrm{pH})$ microenvironment and bone metabolism. It has been claimed that OGR1 can inhibit the growth and proliferation of cancer cells. Moreover, it has been reported that OGR1 can inhibit the metastasis of tumor cells in mice.

To investigate the function of OGR1, the physiological function of breast cancer cells was studied through constructing highly expressed OGR1 via transient transfection of eukaryotic vector using breast cancer cells as the material in this study. 


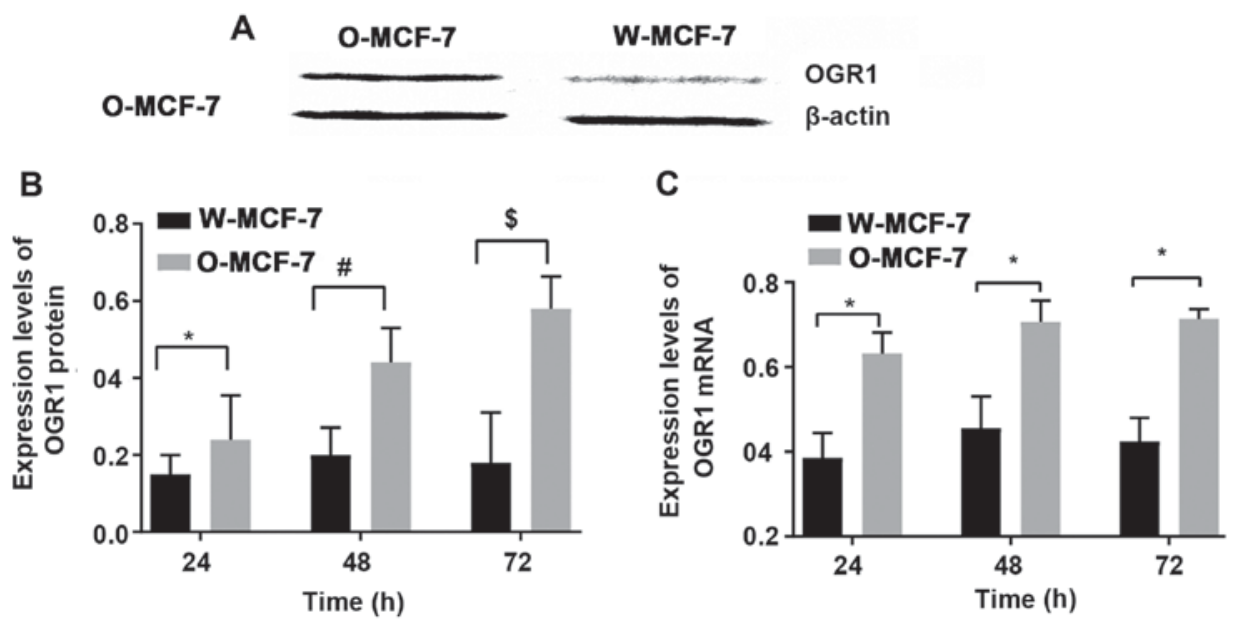

Figure 1. Expression of OGR1 in MCF-7 cells. (A) Detection of OGR1 expression in cells via western blotting. (B) Expression levels of OGR1 protein in different cells at different time points. (C) Expression levels of OGR1 mRNA in different cells at different time points. ${ }^{*} \mathrm{P}<0.05$, the difference between two groups is significant; ${ }^{\mathrm{P}} \mathrm{P}<0.005$, the difference is very significant; ${ }^{\mathrm{S}} \mathrm{P}<0.001$, the difference is extremely significant.

\section{Materials and methods}

Cell culture. MCF-7 cells were cultured according to conventional cell culture methods. Well-grown cells in logarithmic growth phase were used for experiments. After the cells were transfected with pIRESpuro3 vector and pIRESpuro3-OGR1 using Lipofectamine 2000, the culture medium was replaced and the cells continued to be cultured for a certain period of time for detection. The two groups of cells were named W-MCF-7 and O-MCF-7, respectively.

Detection of cell proliferation activity. According to the operation manual, single cell suspension was prepared and inoculated into the culture plate with $100 \mu \mathrm{l}$ cell suspension (approximately $5 \times 10^{3}$ cells) per well. Cell Counting Kit- 8 (CCK8) was adopted for determination of cell proliferation activity at a specific time after transfection.

RT-qPCR detection. According to the instructions, total RNA was extracted using TRIzol (Thermo Fisher Scientific, Inc., Waltham, MA, USA) from the cultured Michigan Cancer Foundation-7 (MCF-7) cells, purified and reversely transcribed to obtain complementary deoxyribonucleic acid (cDNA) with TaqMan microRNA reverse transcription kit (Thermo Fisher Scientific, Inc.). The expression levels of OGR1, serine-threonine kinase (AKT), p53 and other genes were analyzed via qPCR. All reactions were repeated for at least three times. The expression of mRNA was standardized by $\beta$-actin. Calculation of all expression levels was conducted by $2^{-\Delta \Delta C q}$ method (13). All primer pair sequences are summarized in Table I.

Detection of protein expression level in cells via western blotting. The cells that have been cultured for a certain period of time were collected for extraction of total protein in accordance with the use requirements of the kit (total protein extraction kit; Invent Biotechnologies Inc., Plymouth, MN, USA). Protein extracted per lane (10 $\mu \mathrm{l})$ was subjected to $10 \%$ gel electrophoresis and then transferred onto the polyvinylidene fluoride (PVDF) membrane, followed by blocking with 5\%
Table I. Primers used in fluorescence quantitative qPCR assay.

\begin{tabular}{ll}
\hline Name & \multicolumn{1}{c}{ Primer pair } \\
\hline OGR1 & F: AAAGCCAATCAGTGTGGGTATGG \\
& $\begin{array}{l}\text { R: AGGATCTAGGCATCACTGGTGGT } \\
\text { AKT }\end{array}$ \\
& $\begin{array}{l}\text { F: GTGCTGGAGGACAATGACTA } \\
\text { R: AGCAGCCCTGAAAGCAAGGA }\end{array}$ \\
p53 & F: CTGAGGTTGGCTCTGACTGTACCACCATCC \\
& R: CTCATTCAGCTCTCGGAACATCTCGAAGCG \\
$\beta$-actin & F: CTTCCTTCCTGGGCATG \\
& R: GTCTTTGCGGATGTCCAC
\end{tabular}

F, forward; R, reverse.

milk at $20^{\circ} \mathrm{C}$ for $1.5 \mathrm{~h}$. According to the instructions, the mouse anti-human p53, AKT, phosphorylated-AKT (p-AKT) and $\beta$-actin monoclonal antibodies (1:400; cat. nos. sc-47698, sc-81434, sc-81433, 58673 all from Santa Cruz Biotechnology, Inc., Dallas, TX, USA) were added, respectively, for reaction. After the membrane was washed, horseradish peroxidase (HRP)-labeled second goat anti-mouse polyclonal antibody (1:1,200; cat. no. sc-2005; Santa Cruz Biotechnology, Inc.) was added for color development, and the gel imaging analysis system was used for scanning.

Detection of cell apoptosis. For detection of apoptosis, cells cultured for different time were collected and washed with phosphate buffered saline (PBS) three times. The concentration was adjusted to $5 \times 10^{5} / \mathrm{ml}$. Staining was conducted according to the instructions of apoptosis detection kit. BD FACSCalibur (BD Biosciences, Franklin Lakes, NJ, USA) was applied for detection of apoptotic cells.

Statistical analysis. t-test was used for intergroup analysis, and $\mathrm{P}<0.05$ was considered to indicate a statistically significant difference. 

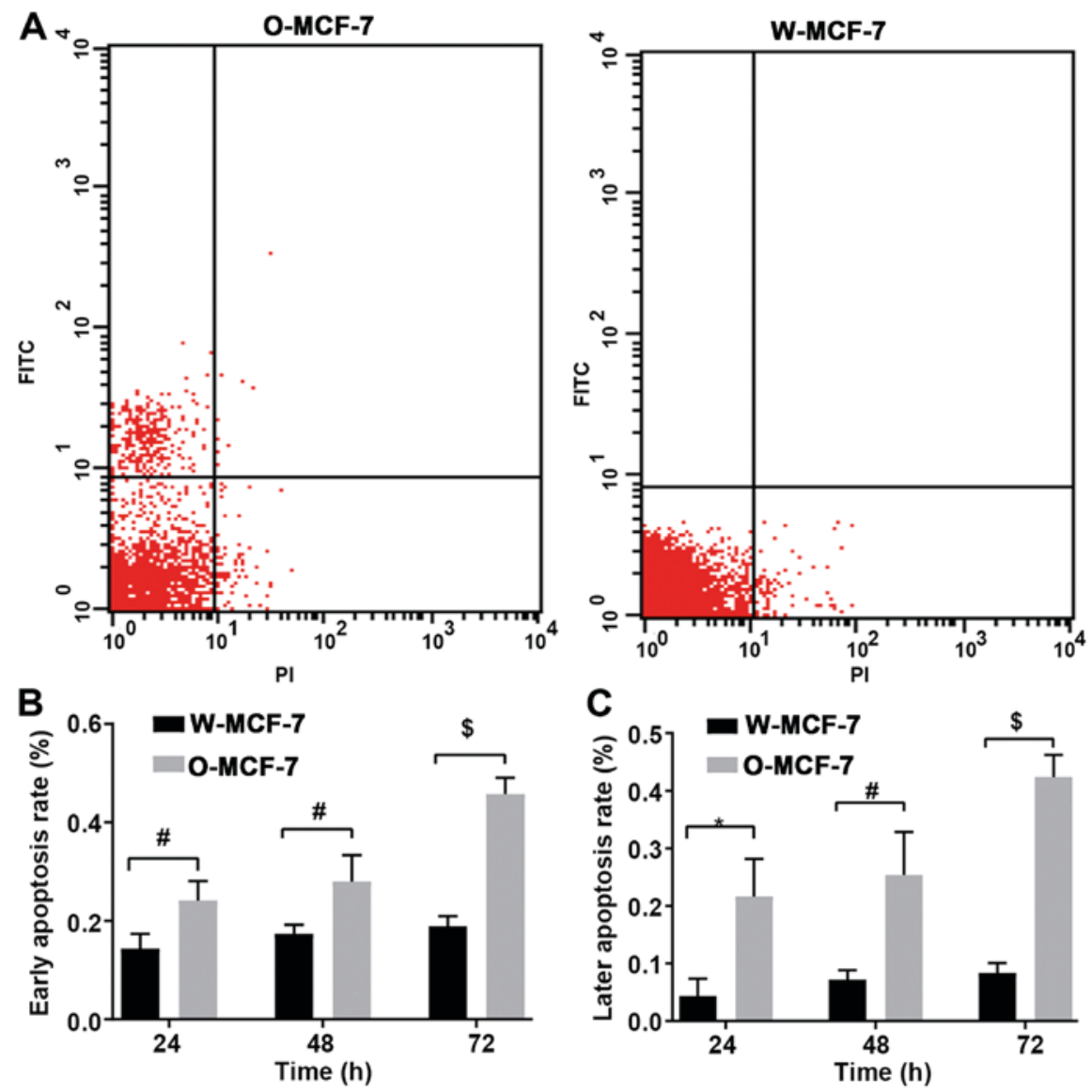

Figure 2. Apoptosis detection. (A) Detection of early and late apoptosis of W-MCF-7 and O-MCF-7 cells by flow cytometry. (B) Early apoptosis rates of $\mathrm{W}-\mathrm{MCF}-7$ and O-MCF-7 cells. (C) Later apoptosis rates of W-MCF-7 and O-MCF-7 cells after detection of transfection for a given time. ${ }^{*} \mathrm{P}<0.05$, the difference between two groups is significant; ${ }^{\#} \mathrm{P}<0.005$, the difference is very significant; ${ }^{~} \mathrm{P}<0.001$, the difference is extremely significant.

\section{Results}

Expression levels of OGR 1 in the two groups of cells. The relative expression levels of OGR1 mRNA at 24, 48 and $72 \mathrm{~h}$ in W-MCF-7 cells were $0.38 \pm 0.06,0.46 \pm 0.08$ and $0.42 \pm 0.06$, respectively, while those in $\mathrm{O}-\mathrm{MCF}-7$ cells were $0.63 \pm 0.05$, $0.70 \pm 0.03$ and $0.70 \pm 0.02$, respectively. The relative expression levels of OGR 1 protein at 24, 48 and $72 \mathrm{~h}$ were $0.15 \pm 0.04$, $0.20 \pm 0.07$ and $0.18 \pm 0.13$, respectively, in W-MCF-7 cells, and $0.24 \pm 0.11,0.44 \pm 0.09$ and $0.58 \pm 0.08$, respectively, in $\mathrm{O}-\mathrm{MCF}-7$ cells. The above results indicated successful transfection of O-MCF-7 cells and successfully high expression of OGR1 protein (Fig. 1).

Detection of apoptosis by flow cytometry. According to the results of flow cytometry, at 24, 48 and $72 \mathrm{~h}$, the early apoptosis rates of $\mathrm{W}-\mathrm{MCF}-7$ cells were $0.144 \pm 0.03,0.17 \pm 0.02$ and $0.19 \pm 0.05 \%$, respectively, while those of cells transfected with $\mathrm{O}-\mathrm{MCF}-7$ were $0.24 \pm 0.04,0.28 \pm 0.05$ and $0.46 \pm 0.03 \%$, respectively, and the late apoptosis rates of $\mathrm{W}-\mathrm{MCF}-7$ cells were $0.04 \pm 0.03,0.07 \pm 0.02$ and $0.08 \pm 0.02 \%$, respectively, while those of $\mathrm{O}-\mathrm{MCF}-7$ cells were $0.22 \pm 0.07,0.25 \pm 0.07$ and $0.42 \pm 0.04 \%$, respectively. The apoptosis rate was markedly decreased in W-MCF-7 group, compared with that in O-MCF-7 group, with a significant difference. Thus it can be seen that OGR 1 can regulate apoptosis through the signal pathway (Fig. 2).

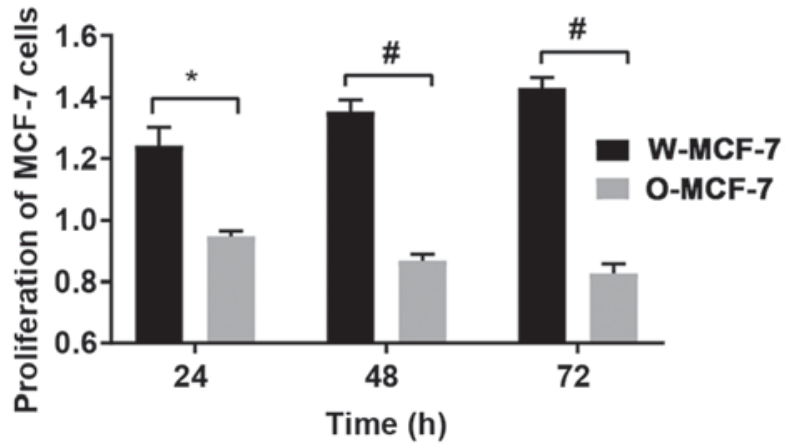

Figure 3. Effects of transfection in vitro at different time points on the proliferation of MCF-7 cells. ${ }^{*} \mathrm{P}<0.05$, the difference between two groups is significant; ${ }^{\#} \mathrm{P}<0.005$, the difference is very significant.

Detection of cell proliferation. At 24, 48 and $72 \mathrm{~h}$, the relative proliferative levels of $\mathrm{W}-\mathrm{MCF}-7$ cells were $1.24 \pm 0.06$, $1.35 \pm 0.04$ and $1.43 \pm 0.03$, respectively, while those of O-MCF-7 cells were $0.95 \pm 0.02,0.87 \pm 0.02$ and $0.83 \pm 0.03$, respectively, suggesting that the upregulation of OGR1 expression can regulate cell proliferation through signal transduction (Fig. 3).

Detection of changes in gene expression via RT-qPCR. At 24, 48 and $72 \mathrm{~h}$, the relative expression levels of p53 mRNA in $\mathrm{W}-\mathrm{MCF}-7$ cells were $0.50 \pm 0.07,0.48 \pm 0.05$ and $0.45 \pm 0.04$, 

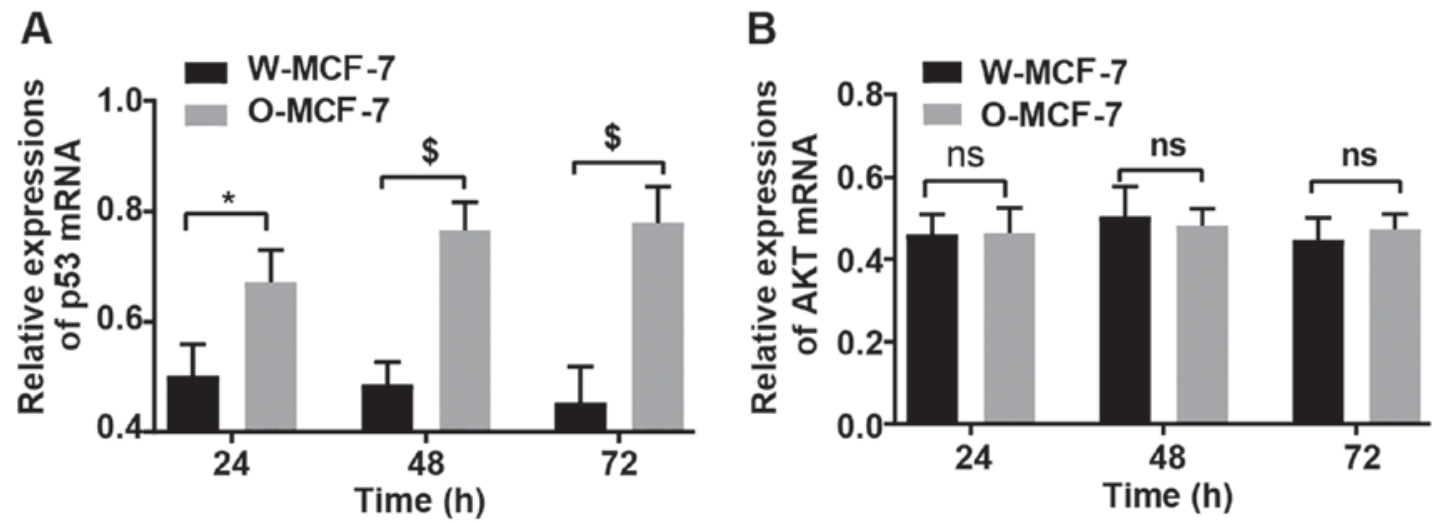

Figure 4. Detection of mRNA relative expression levels of p53 and AKT in cells via fluorescence quantitative PCR. (A) Relative expression levels of p53 mRNA in the two groups of cells at different time points. (B) Relative expression levels of AKT mRNA in the two groups of cells at different time points. ns, no significant difference between the two groups $(\mathrm{P}>0.05)$. $\mathrm{P}<0.05$, the difference between two groups is significant; ${ }^{\text {ns }} \mathrm{P}>0.05$, the difference is no significant; ${ }^{\$} \mathrm{P}<0.001$, the difference is extremely significant.

A

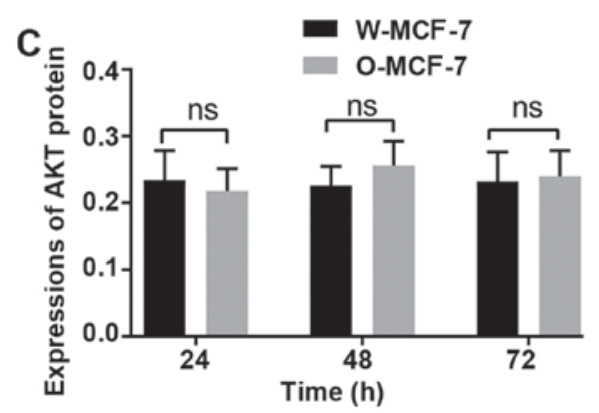

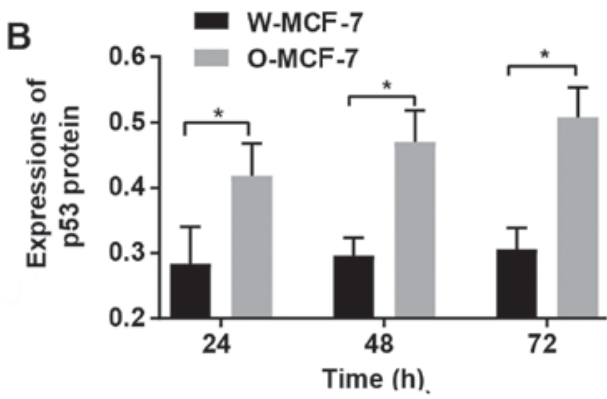

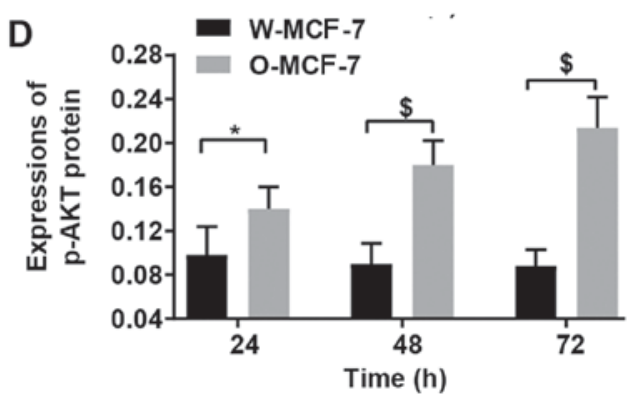

Figure 5. Detection of protein expression. (A) Detection of expression levels of various proteins in W-MCF-7 cells and O-MCF-7 cells. (B) Expression levels of p53 in the two groups of cells after transfection for a given time. (C) Protein expression levels of AKT in W-MCF-7 cells and O-MCF-7 cells after transfection for a given time. (D) Protein expression levels of p-AKT in W-MCF-7 cells and O-MCF-7 cells after transfection for a certain time. ns, no significant difference between the two groups $(\mathrm{P}>0.05)$. ${ }^{\mathrm{P}}<0.05$, the difference between two groups is significant; ${ }^{\text {ns }} \mathrm{P}>0.05$, the difference is no significant; ${ }^{\$} \mathrm{P}<0.001$, the difference is extremely significant.

respectively, while those in O-MCF-7 cells were $0.67 \pm 0.06$, $0.77 \pm 0.05$ and $0.78 \pm 0.07$, respectively. However, the mRNA content of AKT displayed no remarkable difference between the two groups (Fig. 4).

Effects of p53 and AKT protein expression levels. At 24 and 48 and $72 \mathrm{~h}$, the relative expression levels of p53 in W-MCF-7 cells were $0.28 \pm 0.06,0.30 \pm 0.03$ and $0.31 \pm 0.03$, respectively, while those in O-MCF-7 cells were $0.42 \pm 0.05,0.47 \pm 0.04$ and $0.51 \pm 0.05$, respectively. However, the AKT protein content showed no obvious difference between the two groups. The relative expression levels of p-AKT at 24, 48 and $72 \mathrm{~h}$ in W-MCF-7 cells were $10 \pm 0.03,0.09 \pm 0.02$ and $0.09 \pm 0.01$, respectively, and those in $\mathrm{O}-\mathrm{MCF}-7$ cells were $0.14 \pm 0.02$, $0.18 \pm 0.040$ and $0.21 \pm 0.03$, respectively (Fig. 5).

\section{Discussion}

Breast cancer is a major cancer in women that seriously threatens women's health. In particular, breast cancer metastasis can cause serious consequences, leading to higher recurrence and mortality rates. The occurrence of breast cancer is associated with a variety of factors, such as environment, personal life state and heredity, and it involves the intermolecular information transmission within cells, and extracellular or intercellular interactions and signal transmission. The gradual transmission and interactions of these signals alter migration, infiltration and growth processes of tumor cells. Tumor cell growth is a dynamic process regulated and controlled by multiple factors. In this study, the effects of OGR1 on the proliferation and apoptosis of breast cancer 
cells were explored, and the possible mechanism of its action is preliminarily discussed.

The results of apoptosis experiment demonstrated that the highly expressed OGR1 in breast cancer cells could effectively enhance apoptosis. Cell proliferation experiment displayed that the growth and proliferation abilities of breast cancer cells with highly expressed OGR1 were inhibited to some extent,compared with those of breast cancer cells with low expression of OGR1. According to some research, OGR1 deficiency in prostate cancer model of transgenic mice reduces tumor formation $(14,15)$. The expression of OGR1 in metastatic tumors was lower than that in primary prostate cancer tissues. Li et al reported that OGR1 inhibits cell migration through molecular signal transduction pathway in MCF-7 breast cells (16). Recent research has also indicated that OGR1 can activate calcium sensitive protease and its downstream signaling molecules such as Bid, Bax and caspase-3, thus inducing chondrocyte apoptosis in rats (17). These results manifested that OGR1 may act as an inhibitory factor for tumor metastasis. However, the anti-tumor effect of OGR1 needs to be further investigated.

Results of western blotting displayed that the gene and protein expression levels of p53 in breast cancer cells with highly expressed OGR1 were also increased. According to current studies, p53 is a very important tumor suppressor gene in human body, which can inhibit cell cycle progression, mediate cell cycle arrest, inhibit cell proliferation, promote cell senescence and regulate cell apoptosis, thus playing an important role in inhibiting the development of tumors. At the same time, some studies have revealed that regulation of p53 on cell metabolic activity is also an important means of its anti-tumor effect. The decreased p53 gene in human body will increase the occurrence and development of tumors. The results suggest that OGR1 protein and p53 protein interact with each other, transmit information, and further regulate the expression and activity control of downstream or other related proteins, thereby manipulating tumor cells.

Furthermore, the findings of this study indicated that no obvious difference in protein expression of AKT between breast cancer cells with low expressio of OGR1 and those with highly expressed OGR1 was found, but the protein content of $\mathrm{p}-\mathrm{AKT}$ in the latter was reduced. The latest research findings have revealed that the activated AKT protein can regulate the survival state (18) and specific physiological function of cells $(19,20)$ through multiple signaling pathways. Besides, p53 regulates nitric oxide synthase in endothelial cells to regulate tumor angiogenesis $(21,22)$. Finally, AKT can interact with phosphatidylinositol 3-kinase (PI3K) to participate in the invasion and migration of tumor cells $(23,24)$, which is consistent with the fact that OGR1 can inhibit the migration of breast cancer cells (16). Previous research on prostate cancer has manifested that the migration ability of cancer cells with highly expressed OGR1 is inhibited (25).

The results of this study indicated that the expression level of OGR1, which has an effect on the proliferation and apoptosis of breast cancer cells, may be related to the expression levels of p-AKT and p53, and it regulates the expression of related genes, thus influencing the function of breast cancer cells. However, the risk factors of breast cancer are very complicated. The growth of tumor cells is a physiological mechanism regulated by multiple networks. Further studies on the pathogenesis of breast cancer will contribute to understanding the pathogenesis of tumors in a more detail way, providing support for better diagnostic and therapeutic applications.

\section{Acknowledgements}

Not applicable.

\section{Funding}

No funding was received.

\section{Availability of data and materials}

The datasets used and/or analyzed during the current study are available from the corresponding author on reasonable request.

\section{Authors' contributions}

JZ wrote the manuscript. JZ and WS helped with cell culture. LC, JS and MH were responsible for PCR and western blotting. MT detected cell apoptosis. All authors read and approved the final manuscript.

\section{Ethics approval and consent to participate}

The study was approved by the Ethics Committee of Dongying People's Hospital (Dongying, China).

\section{Patient consent for publication}

Not applicable.

\section{Competing interests}

The authors declare that they have no competing interests

\section{References}

1. Sirkisoon SR, Carpenter RL, Rimkus T, Miller L, MethenyBarlow L and Lo HW: EGFR and HER2 signaling in breast cancer brain metastasis. Front Biosci (Elite Ed) 8: 245-263, 2016.

2. Siegel RL, Miller KD and Jemal A: Cancer statistics, 2015. CA Cancer J Clin 65: 5-29, 2015.

3. Fidler IJ: The pathogenesis of cancer metastasis: The 'seed and soil' hypothesis revisited. Nat Rev Cancer 3: 453-458, 2003.

4. Nola S, Sin S, Bonin F, Lidereau R and Driouch K: A methodological approach to unravel organ-specific breast cancer metastasis. J Mammary Gland Biol Neoplasia 17: 135-145, 2012.

5. O'Shaughnessy J: Extending survival with chemotherapy in metastatic breast cancer. Oncologist 10 (Suppl 3): 20-29, 2005.

6. Shao MM, Liu J, Vong JS, Niu Y, Germin B, Tang P, Chan AW, Lui PC, Law BK, Tan PH, et al: A subset of breast cancer predisposes to brain metastasis. Med Mol Morphol 44: 15-20, 2011.

7. Hohensee I, Lamszus K, Riethdorf S, Meyer-Staeckling S, Glatzel M, Matschke J, Witzel I, Westphal M, Brandt B, Müller V, et al: Frequent genetic alterations in EGFR- and HER2-driven pathways in breast cancer brain metastases. Am J Pathol 183: 83-95, 2013.

8. Aragon-Ching JB and Zujewski JA: CNS metastasis: An old problem in a new guise. Clin Cancer Res 13: 1644-1647, 2007.

9. Brufsky AM, Mayer M, Rugo HS, Kaufman PA, Tan-Chiu E, Tripathy D, Tudor IC, Wang LI, Brammer MG, Shing M, et al: Central nervous system metastases in patients with HER2-positive metastatic breast cancer: Incidence, treatment, and survival in patients from registHER. Clin Cancer Res 17: 4834-4843, 2011. 
10. Klein A, Olendrowitz C, Schmutzler R, Hampl J, Schlag PM Maass N, Arnold N, Wessel R, Ramser J, Meindl A, et al: Identification of brain- and bone-specific breast cancer metastasis genes. Cancer Lett 276: 212-220, 2009.

11. Niikura N, Hayashi N, Masuda N, Takashima S, Nakamura R, Watanabe K, Kanbayashi C, Ishida M, Hozumi Y, Tsuneizumi M, et al: Treatment outcomes and prognostic factors for patients with brain metastases from breast cancer of each subtype: A multicenter retrospective analysis. Breast Cancer Res Treat 147: 103-112, 2014.

12. Ludwig MG, Vanek M, Guerini D, Gasser JA, Jones CE, Junker U, Hofstetter H, Wolf RM and Seuwen K: Proton-sensing G-protein-coupled receptors. Nature 425: 93-98, 2003.

13. Livak KJ and Schmittgen TD: Analysis of relative gene expression data using real-time quantitative PCR and the 2(-Delta Delta C(T)) method. Methods 25: 402-408, 2001.

14. Yan L, Chang Z, Liu Y, He BR and Hao DJ: Primary spinal melanoma: A case report and literature review. Chin Med J (Engl) 125: 4138-4141, 2012.

15. Yan L, Singh LS, Zhang L and Xu Y: Role of OGR1 in myeloidderived cells in prostate cancer. Oncogene 33: 157-164, 2014.

16. Li J, Guo B, Wang J, Cheng X, Xu Y and Sang J: Ovarian cancer $\mathrm{G}$ protein coupled receptor 1 suppresses cell migration of MCF7 breast cancer cells via a Ga12/13-Rho-Rac1 pathway. J Mol Signal 8: 6, 2013.

17. Yuan FL, Wang HR, Zhao MD, Yuan W, Cao L, Duan PG Jiang YQ, Li XL and Dong J: Ovarian cancer G protein-coupled receptor 1 is involved in acid-induced apoptosis of endplate chondrocytes in intervertebral discs. J Bone Miner Res 29: 67-77, 2014.

18. Datta SR, Brunet A and Greenberg ME: Cellular survival: A play in three Akts. Genes Dev 13: 2905-2927, 1999.
19. Muise-Helmericks RC, Grimes HL, Bellacosa A, Malstrom SE, Tsichlis PN and Rosen N: Cyclin D expression is controlled post-transcriptionally via a phosphatidylinositol 3-kinase/ Akt-dependent pathway. J Biol Chem 273: 29864-29872, 1998.

20. Mayo LD and Donner DB: A phosphatidylinositol 3-kinase/Akt pathway promotes translocation of $\mathrm{Mdm} 2$ from the cytoplasm to the nucleus. Proc Natl Acad Sci USA 98: 11598-11603, 2001.

21. Michell BJ, Griffiths JE, Mitchelhill KI, Rodriguez-Crespo I, Tiganis T, Bozinovski S, de Montellano PR, Kemp BE and Pearson RB: The Akt kinase signals directly to endothelial nitric oxide synthase. Curr Biol 9: 845-848, 1999.

22. Hurt KJ, Musicki B, Palese MA, Crone JK, Becker RE, Moriarity JL, Snyder SH and Burnett AL: Akt-dependent phosphorylation of endothelial nitric-oxide synthase mediates penile erection. Proc Natl Acad Sci USA 99: 4061-4066, 2002.

23. Kim D, Kim S, Koh H, Yoon SO, Chung AS, Cho KS and Chung J: Akt/PKB promotes cancer cell invasion via increased motility and metalloproteinase production. FASEB J 15: 1953-1962, 2001 .

24. Kubiatowski T, Jang T, Lachyankar MB, Salmonsen R, Nabi RR, Quesenberry PJ, Litofsky NS, Ross AH and Recht LD: Association of increased phosphatidylinositol 3-kinase signaling with increased invasiveness and gelatinase activity in malignant gliomas. J Neurosurg 95: 480-488, 2001.

25. Iremashvili V, Burdick-Will J and Soloway MS: Improving risk stratification in patients with prostate cancer managed by active surveillance: A nomogram predicting the risk of biopsy progression. BJU Int 112: 39-44, 2013.

This work is licensed under a Creative Commons Attribution-NonCommercial-NoDerivatives 4.0 International (CC BY-NC-ND 4.0) License. 